\title{
Pervivencias y transformaciones de la artesanía almeriense
}

Gema Carrera Díaz, Centro de Documentación, IAPH

\section{La artesanía no es un objeto fosilizado que se pueda delimitar o proteger por las vías tradicionales aplicadas a los elementos patrimoniales muebles o inmuebles}

Con el título Artesanías en la provincia de Almería, hemos pretendido centrar esta sección en la vinculación de dos términos, uno cultural y otro toponímico, que, tanto por separado como unidos, brillan por su falta de visualización y valorización histórica en el ámbito de la tutela a escala regional. Nos mueve una inquietud, que en esta nueva etapa del Instituto Andaluz del Patrimonio Histórico va a ir tomando cada vez mayor consistencia: conocer, registrar, valorar y difundir el patrimonio inmaterial de Andalucía atendiendo, no sólo a objetos muebles e inmuebles con unos valores culturales, históricos y/o artísticos reconocidos, sino también a prácticas y procesos sociales, conocimientos, saberes, expresiones que añadan una visión plural con nuevos actores sociales tradicionalmente ausentes y no reconocidos

Almería, la provincia más oriental de Andalucía, rica y diversa desde el punto de vista ecológico-cultural o territorial destaca, entre muchas otras cosas, por sus valores relacionados con la artesanía y con los saberes y oficios artesanos ligados a diferentes contextos y orientados a diversos fines.

Las características físicas, territoriales, las influencias culturales y el devenir histórico de cada una de sus comarcas, se van a reflejar en los diferentes oficios y saberes artesanos que en ellas se han ido generando, evolucionando, transformando $y$, a veces, por la propia dinámica cultural, eliminando. Al mismo tiempo, estas han ido construyendo y definiendo su propio territorio, dibujando su rastro en los diversos paisajes culturales resultantes de esta dialéctica entre medio y cultura.

Es notable la vinculación o la complementariedad histórica existente entre los recursos o materias primas propios de cada territorio (barro, esparto, madera...), las faenas agropecuarias, pesqueras y mineras tradicionales desarrolladas en los mismos, y las labores artesanas proveedoras de los instrumentos necesarios para el trabajo que estos exigen (construcción artesanal de barcos, artes de pesca y elaboración de redes; la cultura parralera y la barrilería, la cerámica, el cultivo y el trabajo del esparto, elaboración de serones, la cestería...); provisión de instrumentos para labores domésticas (la alfarería y la cerámica, la tejeduríajarapas); productos artesanales con protagonismo simbólico y ritual (la pirotecnia y dominio de la pólvora para la elaboración de fuegos artificiales tan empleados en las fiestas almerienses) etcétera. 
(1) Trabajando el esparto. Terque / Foto: JuAn CARLos CAZALLA, IAPH

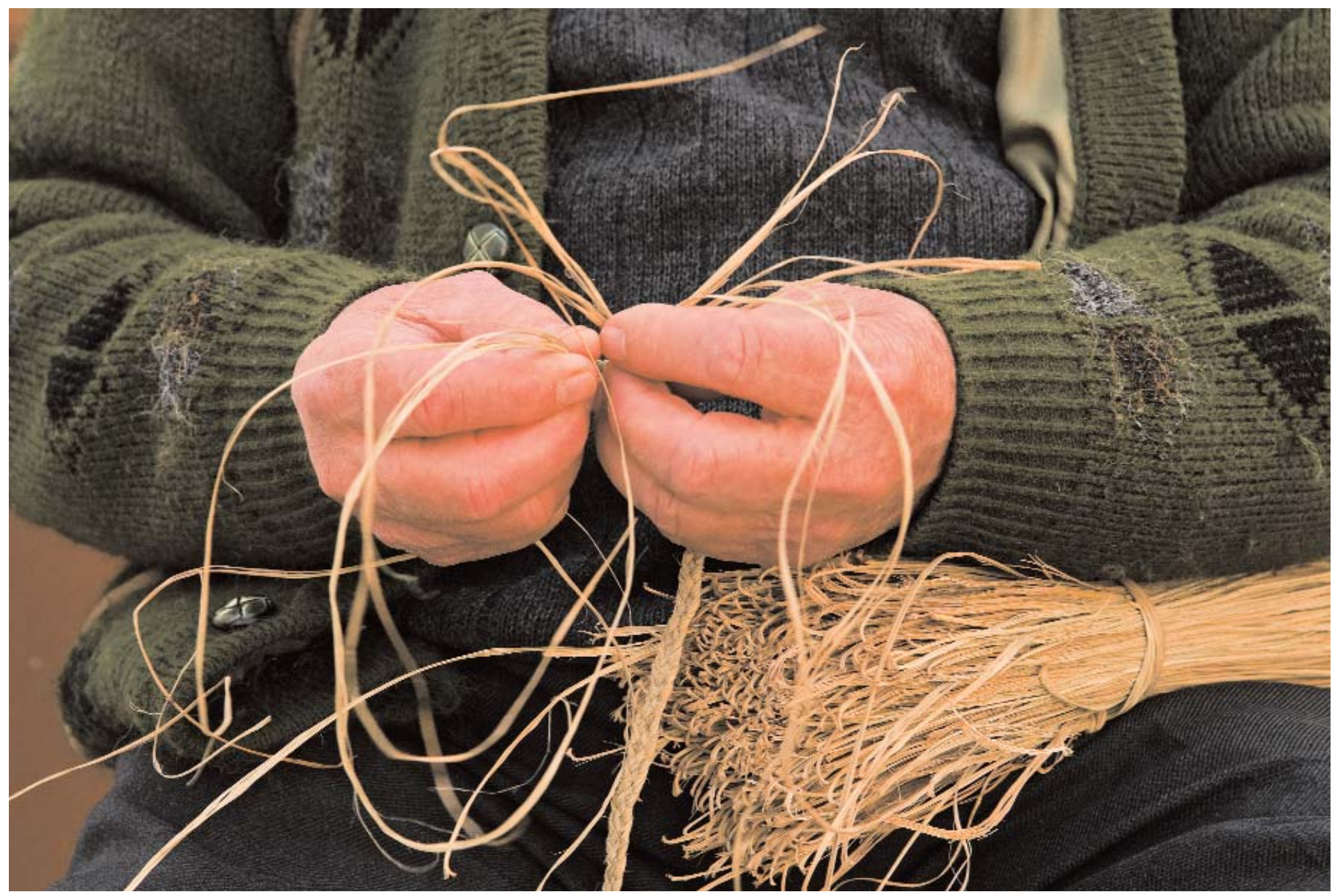


En todo momento enfocamos la artesanía como una expresión cultural viva y en continua transformación, donde la tradición se interpreta como un proceso en continuo cambio, no como una supervivencia del pasado sin funcionalidad vigente. Es decir, los artesanos, con su oficio, producen objetos, pero la artesanía no es un objeto fosilizado que se pueda datar o delimitar o proteger por las vías tradicionales aplicadas a los elementos patrimoniales muebles o inmuebles. Se trata, sin embargo, de un proceso en continuo cambio que ha ido adaptándose a cada momento histórico y asumiendo su propia herencia cultural. Que pervive, o no, en función de esta propia vivacidad, de su capacidad de adaptación, de transmisión y de dotarse de nuevos significados.

Podemos considerar a la artesanía en general y a la almeriense, en particular, según los principios vigentes de sostenibilidad y desarrollo económico, como prácticas deseables: las artesanías están localizadas y reflejan las características ecológico-culturales de su entorno; son respetuosas con el medio ambiente, aprovechando de forma ecológica las materias primas y los recursos locales; fijan la población rural; estabilizan la pequeña y mediana empresa; son fuentes de divisas mediante la venta directa a los visitantes y turistas o mediante la exportación de sus propios productos y, lo más importante, constituyen un elemento en el que se ven reflejados e identificados los colectivos sociales que las producen y las usan.

Actualmente algunos de estos conocimientos artesanos están en vías de desaparición, debido a la imposibilidad de adaptarse a las nuevas reglas del juego. Una actuación coherente desde el punto de vista patrimonial debe ir orientada, no tanto a "proteger" el inmueble donde se trabaja o el producto elaborado, sino a fomentar y apoyar la continuidad de la actividad en sí, mediante la transmisión del saber, el aprendizaje, la amortiguación de la competencia industrial, el mejor acceso a las materias primas, etc.
Es el proceso social y no el objeto producido lo que se debe preservar para garantizar la creatividad continuada de los diferentes colectivos o individuos artesanos. "La preservación debe estar encaminada a hacer posible que quienes son depositarios de culturas tradicionales continúen ofreciendo modelos alternativos de comportamiento y criterios diferentes de 'éxito' a los encarnados en las formas de vida que compiten con ella" (PROTT, 2001).

En esta sección, a partir de diferentes aportaciones, podremos recorrer algunas, que no todas, de las manifestaciones más características de la artesanía almeriense: la alfarería, sus pervivencias y transformaciones; la tradición pirotécnica en función de los rituales festivos almerienses; la cultura parralera, la uva de barco y la barrilería de Terque; la tradición espartera almeriense y su vinculación con el paisaje y la cultura del trabajo propia de Campos de Níjar; la actividad pesquera y las labores artesanales relacionadas. Debido a la falta de espacio, se han quedado muchas otras actividades artesanales en el tintero, pero se ha hecho evidente parte de la gran diversidad y riqueza cultural de este territorio.

Por otro lado, algunas aportaciones, tratan de exponer medidas que se llevan a cabo desde diferentes instancias locales, provinciales, regionales o estatales que puedan servir de ejemplo en las diferentes facetas de la tutela patrimonial: ya sea desde el conocimiento (FARCA, Fondo Andaluz de Recuperación del Conocimiento Artesano); valorización (Museos de Terque y FARCA); y en última instancia para su continuidad o salvaguarda (Delegación Provincial de Cultura, Plan de Fomento de la Artesanía de Andalucía, de la Consejería de Turismo, Comercio y Deporte, Observatorio de la Artesanía). 


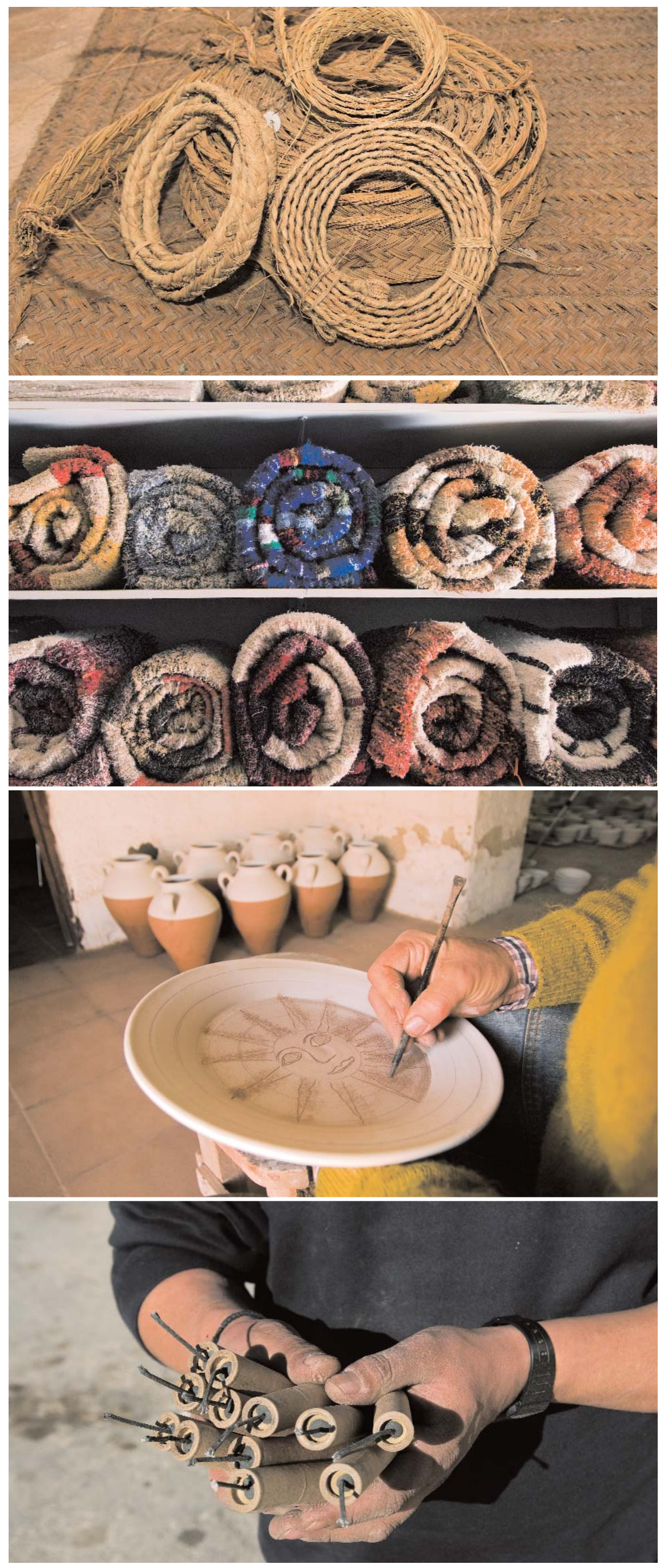

- Museo Histórico Etnográfico de Terque /

FOTO: JUAN CARLOS CAZALLA, IAPH

(2) Jarapas de nijar / Foto: Juan Carlos

CAZALLA, IAPH

(2) Decorando las piezas. Alfarería Los Puntas de Albox / Foto: JUAn CARLos CAZALLA, IAPH

(2) Preparación de carretillas. Festividad de las Carretillas y los Roscos. Olula del Río / Foto: JUAN CARLOS CAZALLA, IAPH 